\title{
Chemical Heat Storage for Saving the Exhaust Gas Energy in a Spark Ignition Engine
}

\author{
Duc Luong Cao, Guang Hong, and Jianguo Wang
}

\begin{abstract}
This study was aimed to develop a chemical heat storage system using magnesium hydroxide $\left(\mathrm{Mg}(\mathrm{OH})_{2}\right)$ and its dehydration and hydration reactions to recover the energy wasted in internal combustion engines (IC engine). The thermal energy of exhaust gas will be stored in the dehydration of $\mathrm{Mg}(\mathrm{OH})_{2}$ to become $\mathrm{MgO}$ and $\mathrm{H}_{2} \mathrm{O}$, and to release in the hydration of MgO. Experiments were conducted on a 6-cylinder spark ignition engine to estimate the amount of energy loss in the exhaust gas and the reactor efficiency in the dehydration process. The stored heat used to heat fresh air from the ambient temperature to more convenient temperature. Results of the preliminary investigation show that the proposed chemical heat storage system is feasible to recover approximately $5.8 \%$ of the heat loss and the temperature of the air is from $275.5 \mathrm{~K}$ to 305.4 $\mathrm{K}$ (with the ambient temperature is from $253 \mathrm{~K}$ to $283 \mathrm{~K}$ and the water vapor pressure is $47 \mathrm{kPa}$ ).
\end{abstract}

Index Terms-Chemical heat storage system, material, heat transfer.

\section{INTRODUCTION}

In a vehicle, around $71 \%$ of the fuel's energy is lost and almost heat loss through exhaust gas and cooling system (Fig. 1). Recovery of waste heat not only directly increases the engine efficiency but also reduces the environment pollution level and improves fuel consumption.

Energy storage is a method used to store energy wasted in a power system and use the stored energy when it is needed. There are two mail groups of energy store: electrical and thermal [1]. Electrical energy storage includes electrochemical systems, kinetic energy storage systems and potential energy storage. In the electrical energy storage, the exhaust gas heat is transferred to electricity and stored in the battery. Sensible, latent and chemical heat storages are classified as thermal energy storage. In this method, exhaust gas heat is stored as internal energy change of a material such as sensible heat, latent heat or thermochemical.

This study focuses on applying the chemical heat storage technology to store engine's wasted heat.

\section{Chemical Heat Storage Technology}

\section{A. Chemical Heat Storage Fundamental}

Chemical heat storage technology uses the chemical materials as heat storage materials. The mail principle of

Manuscript received November 18, 2016; revised May 17, 2017.

The authors are with University of Technology Sydney, Australia (e-mail: ducluong.cao@student.uts.edu.au,

Jianguo.Wang@uts.edu.au). chemical heat storage technology based on a reversible reaction as follows:

$$
\mathrm{A}+\text { heat } \leftrightarrow \mathrm{B}+\mathrm{C}
$$

In the charging process, a thermochemical material $\mathrm{A}$ absorbs heat to become two components $\mathrm{B}$ and $\mathrm{C}$ ( $\mathrm{B}$ and $\mathrm{C}$ are stored separately). During the discharging process, the reverse reaction occurs when two components $\mathrm{B}$ and $\mathrm{C}$ are combined to become A and heat is released.

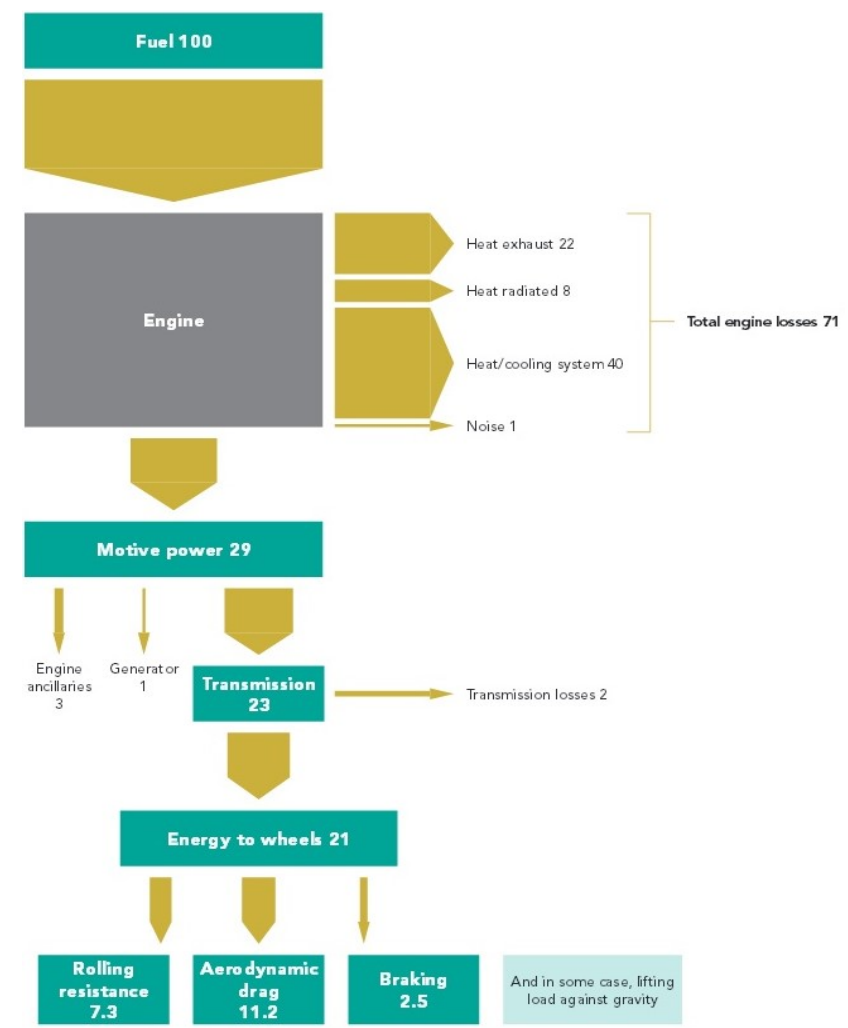

Fig. 1. Example map of energy flows in a vehicle [2]

In the chemical heat storage technology, heat is stored in chemical materials, so it has several advantages over others types of thermal energy storage systems as follows:

1) Chemical heat storage has higher energy density compared with physical energy storage (sensible heat change or phase change) [3].

2) Heat can be stored for a long period and with small heat loss. Chemical materials are stored separately, and in the ambient condition, so the heat lost to the environment is minimal.

\section{B. The Latest Applications of Chemical Heat Storage} Technology in the Internal Combustion Engine Vehicles In the design of KABUSHIKI KAISHA TOYOTA 
JIDOSHOKKI was published on $5^{\text {th }}$ May 2016 [4], a chemical heat storage device was created to warm up the catalyst when starting the engine. A catalytic converter using in a vehicle to purify environment harmful elements such as $\mathrm{CO}_{2}, \mathrm{CO}, \mathrm{NO}_{\mathrm{x}}, \mathrm{HC}$ contained in the exhaust gas and the lowest limit for optimal temperature (for purification performance) of a catalyst is $150{ }^{\circ} \mathrm{C}$ [4]. The temperature of exhaust gas immediately after starting the engine is around $100{ }^{0} \mathrm{C}$ not enough for the operation of the catalyst so in this case the chemical heat storage device was used for warning up the catalyst to reach the active temperature in a short time. The exhaust gas purification system includes a chemical heat storage device are showed in Fig. 2:

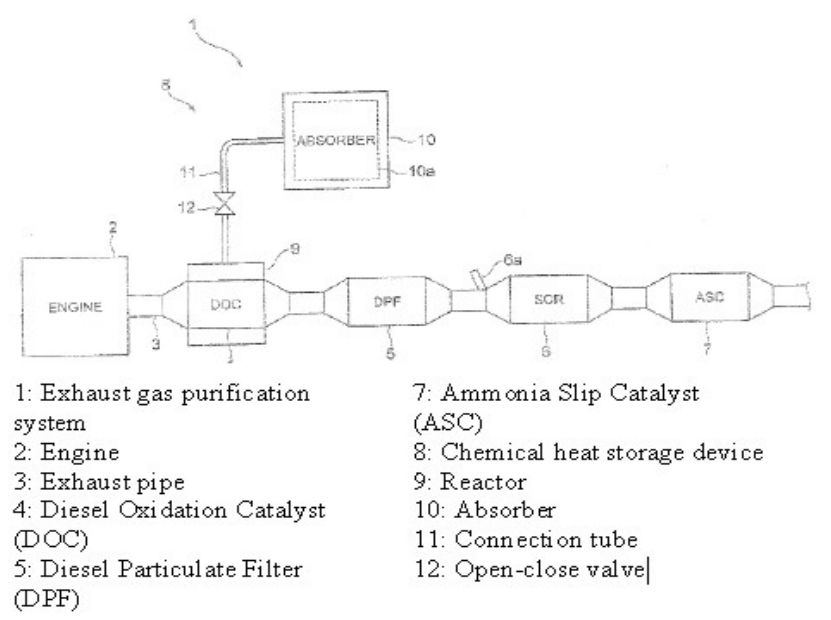

Fig. 2. The exhaust purification system [4].

When starting the engine and the temperature of exhaust gas is lower than the active temperature, the open-close valve is opened, and ammonia from the absorber is transferred to the reactor through a connection tube. Heat creating from the chemical reaction between ammonia and reaction material inside the reactor is transferred to exhaust piper, whereby the temperature of DOC is increased to its active temperature.

Next time, when the temperature of the exhaust gas is higher than the active temperature of the catalysts, the dehydration reaction is taken place in the reactor under the exhaust gas heat, thereby generating ammonia. Through the connection valve, ammonia transfers from the reactor to the absorber and is absorbed by an absorbent.

The difference with the device of KABUSHIKI KAISHA TOYOTA JIDOSHOKKI, this research focuses on applying the chemical heat storage system to cover exhaust gas heat and use it to heat the fresh air. Fresh air after that is used for heating purposes, such as defogging and heating system or fuel heating for the cold-start process.

\section{The INITIAL DESIGN OF CHEMICAL HeAt Storage DEVICE FOR SAVING EXHAUST ENERGY IN A SPARK IGNITION ENGINE}

\section{A. 6-Cylinder Spark Ignition Toyota Aurion Engine}

In the present study, experiments were conducted on a 6-cylinder spark ignition Toyota Aurion engine at the stoichiometric air/fuel ratio. The major specifications of the engine are provided in Table I.
TABLE I: MAJOR SPECIFICATIONS OF THE TESTED ENGINE

\begin{tabular}{lll}
\hline \hline Parameters & Unit & Value \\
\hline Number of cylinders & & 6 \\
Number of strokes & $\mathrm{mm}$ & 94 \\
Bore & $\mathrm{mm}$ & 83.10 \\
Stroke & $\mathrm{cc}$ & 3456 \\
Displacement volume & $\mathrm{mm}$ & 147 \\
Connecting red length & & $10.8: 1$ \\
Compression ration & $\mathrm{kW}$ & $200 @ 6200 \mathrm{rpm}$ \\
Maximum power & $\mathrm{N} . \mathrm{m}$ & $336 @ 4700 \mathrm{rpm}$ \\
Maximum Torque &
\end{tabular}

The engine thermal efficiency and the heat lost in the exhaust gas are determined through experiments were conducted on the engine at the stoichiometric air-fuel ratio. The exhaust gas energy was calculated based on the temperature of exhaust gas (was measured by a thermocouple installed at the exhaust port) and its components (were acquired by Horiba MEXA-584L gas analyser). Heat energy of exhaust gas is the sum of the energy of components and is showed in Fig. 3.

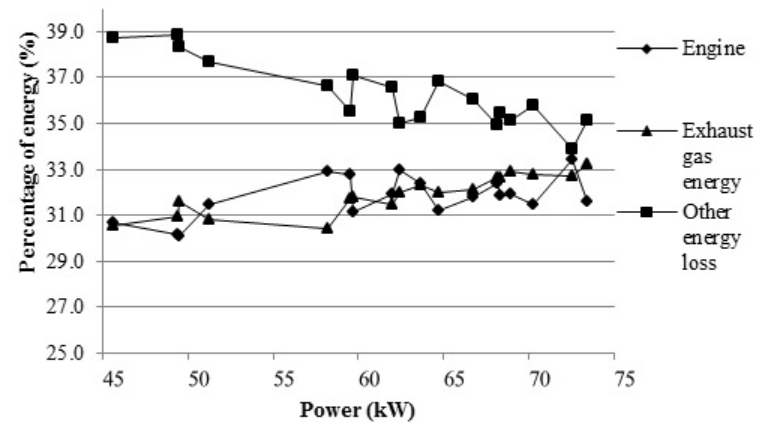

Fig. 3. The energy consumption of 6-cylinder spark ignition engine.

Fig. 3 shows that in the stoichiometric process $(\lambda=1)$, the average heat loss in the exhaust gas, $31.93 \%$ of total energy, is significant and the aim of the current study is to cover part of the energy loss to heat fresh air.

\section{B. Thermochemical Material}

The chemical material adopted is Magnesium hydroxide $\left(\mathrm{Mg}(\mathrm{OH})_{2}\right)$, an environmentally friendly material and its working temperature is suitable for the temperature of the engine outlet exhaust gas.

The thermal conductivity of the packed bed of $\mathrm{Mg}(\mathrm{OH})_{2}$ pellets is too low within $0.15-0.16 \mathrm{~W} / \mathrm{m} . \mathrm{K}$ [5]. The decreased thermal conductivity of pure $\mathrm{Mg}(\mathrm{OH})_{2}$ pellets reduces the heat absorption capacity of chemical material and thereby decreases the efficiency of the reactor. To increase the heat transfer efficiency of chemical material, a new $\mathrm{Mg}(\mathrm{OH})_{2}$ compound was suggested by Massimiliano was the combination of $\mathrm{Mg}(\mathrm{OH})_{2}$ and expanded graphite with the mass mixing ratio 8:1 and in the block state (EM8 block) [5]. As reported in [5], the advantages of this material compared with pure $\mathrm{Mg}(\mathrm{OH})_{2}$ include:

1) Higher thermal conductivity: The thermal conductivity of EM8 block is about ten times that of the pure $\mathrm{Mg}(\mathrm{OH})_{2}$ pellets.

2) Higher density: Compare with the density of the bed with pure $\mathrm{Mg}(\mathrm{OH})_{2}$ pellets were randomly arranged in the reactor, the density of EM8 block is 1.6 times that of 
$\mathrm{Mg}(\mathrm{OH})_{2}$ pellets. With higher density, the capacity of the energy storage system will be increased.

3) Reduced void fraction of the bed will enhance the contact between the packed material and the inner surface and consequently improve the thermal conductivity of the reactor.

As investigated by Massimiliano [5], the volumetric heat storage of EM8 block and other compounds are showed in Fig. 4.

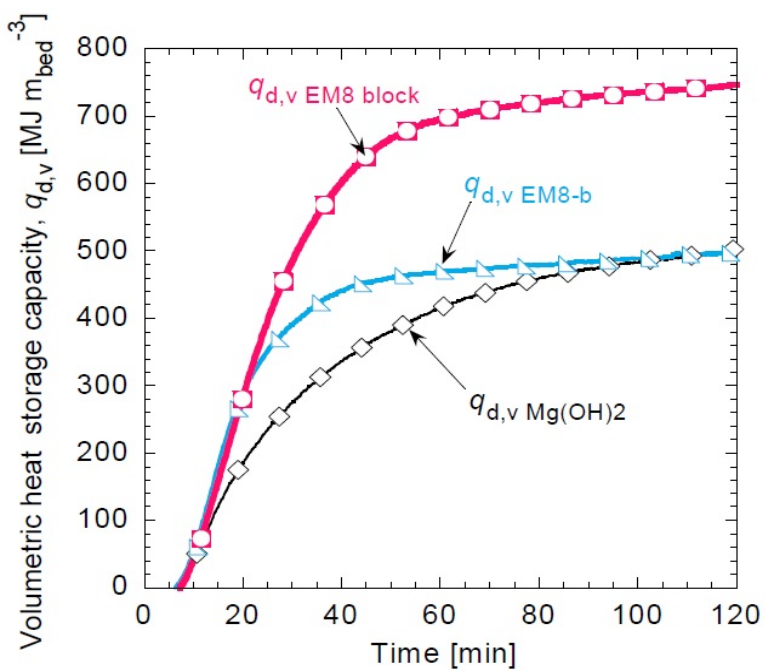

Fig. 4. Comparison of volumetric heat storage capacity of pure $\mathrm{Mg}(\mathrm{OH}) 2$, EM8 in the pellets state and EM8 block [5].

As shown in Fig. 4, the heat storage capacity of EM8 block is 1.4 times higher than pure $\mathrm{Mg}(\mathrm{OH})_{2}$ and EM8-b (the combination of $\mathrm{Mg}(\mathrm{OH})_{2}$ and expanded graphite in the mass mixing ratio is $8: 1$ and in the state of pellets) in one hour working time.

The volumetric heat storage capacity of EM8 block can be estimated using (2) [5]:

$$
q_{d, v}=\frac{-\Delta H_{r}^{0}}{M_{M g(\mathrm{OH})_{2}}} \cdot \Delta x_{d} \cdot r_{m i x} \cdot \rho_{b e d}
$$

where

$q_{d, v}$ is the volumetric storage capacity.

$M_{\mathrm{Mg}(\mathrm{OH})_{2}}$ is mole mass of $\mathrm{Mg}(\mathrm{OH})_{2}(58.322 \mathrm{~g} / \mathrm{mol})$.

$r_{\text {mix }}$ is the mass mixing ration.

$\rho_{\text {bed }}$ is the density of the packed bed ( $\rho_{\text {EM } 8 \text { block }}$ is 1.002 $\left.\mathrm{g} / \mathrm{cm}^{3}\right)$.

$\Delta x_{d}$ is the mole reacted fraction change.

The mass mixing ratio is expressed as follows:

$$
r_{m i x}=\frac{m_{\mathrm{Mg}(\mathrm{OH})_{2}}}{m_{\text {bed }}}
$$

The mole reacted fraction change is showed in (4):

$$
\Delta_{x}=x-x_{i n i}
$$

$x$ is the reacted fraction and

$$
x=1+\frac{\Delta m / M_{\mathrm{H}_{2} \mathrm{O}}}{m_{\mathrm{Mg}(\mathrm{OH})_{2}} / M_{\mathrm{Mg}(\mathrm{OH})_{2}}}
$$

where $\Delta \mathrm{m}$ is the mass of water vapour moving out of the reactor. $m_{\mathrm{Mg}(\mathrm{OH})_{2}}$ is the initial mass of $\mathrm{Mg}(\mathrm{OH})_{2}$ in the reactor. $M_{H_{2}}$ O is the molecule weight of the water $(18.01 \mathrm{~g} / \mathrm{mol})$.

The properties of EM8 block are shown in Table II [5].

\begin{tabular}{lcl}
\multicolumn{3}{c}{ TABLE II: EM8 BLOCK PROPERTIES } \\
\hline \hline Parameters & Unit & Value \\
\hline Mass mixing ratio $\left(\mathrm{r}_{\text {mix }}\right)$ & & $8: 9$ \\
Density of bed & $\mathrm{g} / \mathrm{cm}^{3}$ & 1.002 \\
Heat storage capacity in 1 hours & $\mathrm{MJ} / \mathrm{m}^{3}$ & 700 \\
\hline \hline
\end{tabular}

\section{Chemical Heat Storage Mode}

To store the heat of the exhaust gas, it was proposed that two main devices would be installed in the exhaust gas pathway, a reactor and a condenser/evaporator (condenser in the heat storage and evaporator in the heat output process). The reactor is installed between the engine exhaust port and the catalytic converter.

In the charging process, Magnesium hydroxide absorbs wasted heat of the exhaust gas and converts to magnesium oxide and water vapor in the dehydration reaction of magnesium hydroxide in the reaction chamber. The equilibriums are expressed as follows:

$$
\begin{gathered}
\mathrm{Mg}(\mathrm{OH})_{2}(\mathrm{~s})+\Delta \mathrm{H}_{1} \rightarrow \mathrm{MgO}(\mathrm{s})+\mathrm{H}_{2} \mathrm{O}(\mathrm{g}) \\
\mathrm{H}_{2} \mathrm{O}(\mathrm{g}) \rightarrow \mathrm{H}_{2} \mathrm{O}(\mathrm{l})+\Delta \mathrm{H}_{2}
\end{gathered}
$$

During this process, the $\mathrm{MgO}$ is retained inside the reactor chamber, and the water vapor produced from the chemical reaction is moved into a condenser/evaporator and condensates to the liquid state, as shown in Fig. 5.

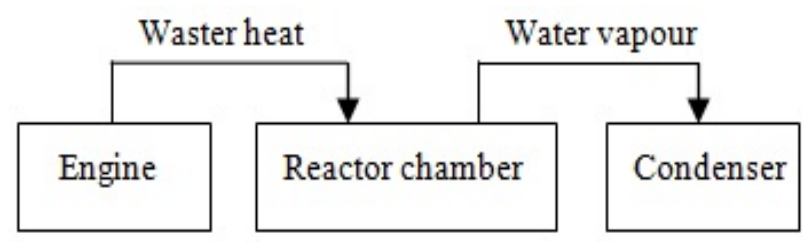

Fig. 5. The heat storage process.

Magnesium oxide and water vapor produced from the reaction are stored separately so that they can be stored for a long time with small heat loss.

In the discharging mode as shown in Fig. 6, the water liquid in the condenser is heated by a small electrical resister to evaporate.

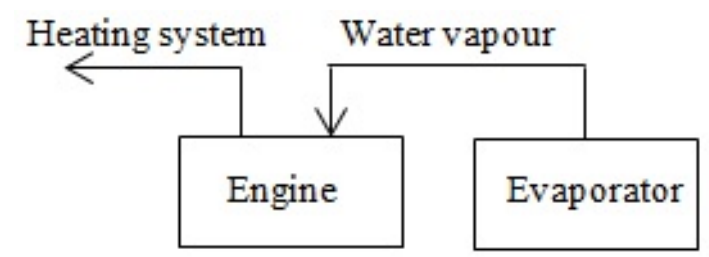

Fig. 6. The heat output process. 
Before heating, water liquid is stored in the evaporator at low pressure and with small volume. Therefore, the energy required for evaporating the liquid water is small compare with the stored exhaust gas energy. The water vapor flows from the evaporator into the reactor chamber. The reaction takes place between the $\mathrm{MgO}$ and the water vapor, $\mathrm{H}_{2} \mathrm{O}(\mathrm{g})$, and heat energy is released in this reaction. The equilibriums are described as follows:

$$
\begin{gathered}
\mathrm{H}_{2} \mathrm{O}(\mathrm{l})+\Delta \mathrm{H}_{3} \rightarrow \mathrm{H}_{2} \mathrm{O}(\mathrm{g}) \\
\mathrm{MgO}(\mathrm{s})+\mathrm{H}_{2} \mathrm{O}(\mathrm{g}) \rightarrow \mathrm{Mg}(\mathrm{OH})_{2}(\mathrm{~s})+\Delta \mathrm{H}_{4}
\end{gathered}
$$

\section{Reactor Design}

The material chosen to fabricate the reactor is steel grade $153 \mathrm{MA}^{\mathrm{TM}}$ that has the maximum service temperature $(1273 \mathrm{~K})$ higher than the maximum temperature of exhaust gas (1065 K in the current study or $1113 \mathrm{~K}$ in Tianyou experiments [6]). The properties of the reactor material are shown in Table III

\begin{tabular}{|c|c|c|}
\hline Properties & Unit & Value \\
\hline Maximum service temperature & $\mathrm{K}$ & 1273 \\
\hline Mass density & $\mathrm{g} / \mathrm{cm}^{3}$ & 7.8 \\
\hline Thermal conductivity & $\mathrm{W} / \mathrm{m} . \mathrm{K}$ & 25.5 \\
\hline Heat capacity & $\mathrm{J} / \mathrm{kg} \cdot \mathrm{K}$ & 500 \\
\hline
\end{tabular}
[7].

The initial design was created based on the experimental results (the temperature and components of the exhaust gas) and in one hour working time.

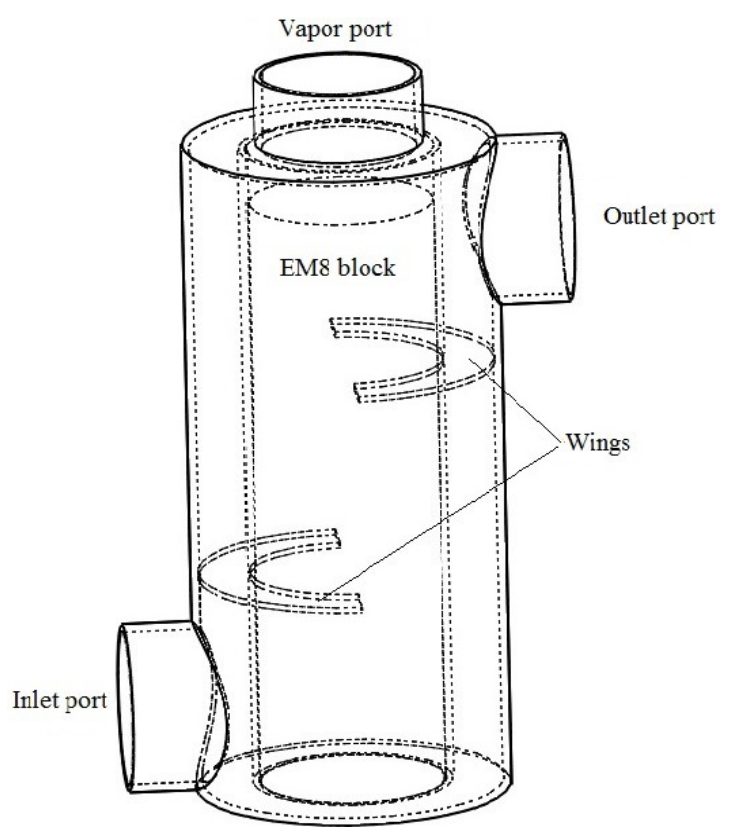

Fig. 7. The reactor design.

Fig. 7 shows the initial design of the reactor. The reactor consists of two tubes: inner and outer tubes. EM8 block is stored inside the inner tube, and the exhaust gas flows in the space between the two tubes. Parameters of the reactor are showed in Table IV.

In the dehydration process, the exhaust gas flows in the space between the two tubes from the inlet port to the outlet port and heat is transferred from the exhaust gas to EM8 block. Under the heat energy from the exhaust gas, the dehydration reaction takes place inside the inner tube. Water vapor from the dehydration reaction of $\mathrm{Mg}(\mathrm{OH})_{2}$ flows out of the reactor from the vapor port placed at the top of the reactor. In the space between two tubes, two wings are designed to make the temperature inside the reactor becomes even, and to increase the moving time of the exhaust gas flow in the reactor thereby to increase the heat transfer efficiency of the reactor.

In the hydration process, the water vapor from the evaporator (water liquid is reheated by an electrical resister and evaporates at the evaporation pressure) flows to the reactor through vapor port. The hydration reaction is taken place inside the reactor and heat transfer from thermochemical material to fresh air through the inner tube wall. Low-temperature fresh air comes to the reactor at the inlet port, receives heat from thermochemical material and higher temperature fresh air moves out of the reactor at the outlet port to transfer to the heating system.

TABLE IV: THE REACTOR PARAMETERS

\begin{tabular}{lcc}
\hline \hline Parameters & Unit & Value \\
\hline \multirow{2}{*}{$\begin{array}{cc}\text { Inner tube } \\
\text { Diameter }\end{array}$} & $\mathrm{mm}$ & 100 \\
Thickness & Outer tube & 3.05 \\
& $\mathrm{~mm}$ & \\
Diameter & $\mathrm{mm}$ & 160 \\
Thickness & mm & 3.05 \\
& $\mathrm{~mm}$ & \\
Diameter & Wings & 88.9 \\
Thickness & $\mathrm{mm}$ & 3.05 \\
& $\mathrm{~mm}$ & 160 \\
External diameter & $\mathrm{mm}$ & 53.05 \\
Internal diameter & & 3.05 \\
Thickness & Outlet and Vapor port & \\
\hline \hline
\end{tabular}

\section{CFD Simulation RESUlts}

\section{A. The Dehydration Process}

The temperature at the inlet of the reactor is assumed to be equal to the temperature at the engine exhaust port. This temperature and the exhaust gas components were acquired by Horiba MEXA-584L gas analyser are given in the Table V.

TABLE V: EXHAUST GAS INLET PARAMETERS

\begin{tabular}{lll}
\hline \hline Properties & Unit & Value \\
\hline Temperature & $\mathrm{K}$ & 1028 \\
$\mathrm{CO}$ & \%vol & 0.1 \\
$\mathrm{CO} 2$ & $\% \mathrm{vol}$ & 15.5 \\
$\mathrm{HC}$ & $\mathrm{ppm}$ & 9.9 \\
$\mathrm{NOx}$ & $\mathrm{ppm}$ & 2335.7 \\
$\mathrm{O} 2$ & \%vol & 0.2 \\
\hline \hline
\end{tabular}

ANSYS Fluent was used to simulate the gas flows and heat transfer in the reactor. The input data are the initial design parameters, exhaust gas parameters and reactor material's thermochemical properties. 
As the temperature of the exhaust gas at the engine exhaust port is high $(1028 \mathrm{~K})$, the mixed thermal condition (combination of convection and radiation) model was chosen to simulate the heat transfer between the exhaust gas and the reactor walls.

EM8 block is assumed as a solid material, so the heat transfer process inside the EM8 block is assumed as the heat conduction process with the properties given in Table II.

It is assumed that the heat absorption process of EM8 block does not vary with time in one hour working time. The heat storage capacity in 1 hour is $700 \mathrm{MJ} / \mathrm{m}^{3}$.Equivalently the heat generator rate is $194.4 \mathrm{~kW} / \mathrm{m}^{3}$.

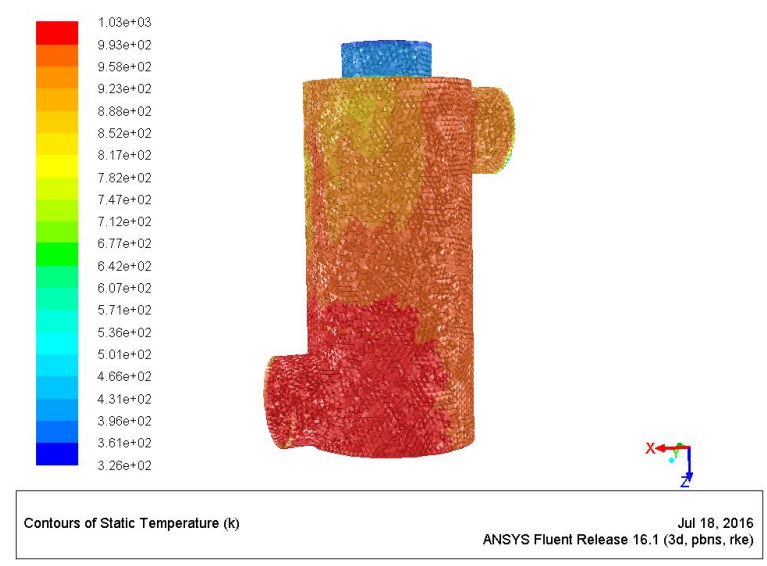

Fig. 8. The temperature of exhaust gas inside the reactor.

Simulation result in Fig. 8 shows that the average temperature of exhaust gas over the cross section of exhaust gas outlet port is approximately $985 \mathrm{~K}$. This temperature was used to calculate the heat energy of exhaust gas at the outlet, and the amount of heat stored in the reactor.

As shown in Table VI, with a small reactor and in one hour operating time, the chemical heat storage device can store $5.8 \%$ heat loss in the exhaust gas. The amount of stored heat depends on the size of the reactor, the temperature of exhaust gas at the exhaust gas inlet and the vehicle operating time.

TABLE VI: ENERGY STORED IN THE REACTOR

\begin{tabular}{|c|c|c|}
\hline Properties & Unit & Value \\
\hline $\begin{array}{l}\text { Heat energy at the inlet of the } \\
\text { reactor }\end{array}$ & $\mathrm{kW}$ & 61.91 \\
\hline $\begin{array}{l}\text { Temperature at the outlet of the } \\
\text { reactor }\end{array}$ & $\mathrm{K}$ & 985 \\
\hline $\begin{array}{l}\text { Heat energy at the outlet of the } \\
\text { reactor }\end{array}$ & $\mathrm{kW}$ & 58.27 \\
\hline Energy stored in the reactor & $\mathrm{kW}$ & 3.64 \\
\hline $\begin{array}{l}\text { Percentage of exhaust heat is } \\
\text { stored }\end{array}$ & $\%$ & 5.8 \\
\hline Volume of EM8 block & $\mathrm{dm}^{3}$ & 2.51 \\
\hline Mass of EM8 block & $\mathrm{kg}$ & 2.51 \\
\hline
\end{tabular}

EM8 block is stored in the reactor in the block state with the outer surface of EM8 block fits with the inner face of the inner tube of the reactor so the volume and mass of EM8 block can be calculated through reactor parameters. As shown in Table VI, to store $5.8 \%$ of exhaust gas heat, the amount of EM8 block required is $2.51 \mathrm{~kg}$. This mass is enough to use in one hour. After this period, almost $\mathrm{Mg}(\mathrm{OH})_{2}$ in EM8 block is converted to $\mathrm{MgO}$ and heat is stored in the reactor.

\section{B. The Hydration Process}

Chemical heat storage device is used to heat fresh air at the low ambient temperature to use for heating purposes, such as defogging and heating system or fuel heating for the cold-start process.

The hydration pressure $\mathrm{P}_{\mathrm{h}}$ (water vapor pressure at the evaporator) affects directly to the temperature, the volumetric heat output of EM8 block and the mole reacted fraction change of the hydration process $\Delta \mathrm{x}_{\mathrm{h}}$ [8]. The properties of EM8 block in the hydration process at the hydration pressure of $47 \mathrm{kPa}, 101 \mathrm{kPa}$ and $361 \mathrm{kPa}$ are showed in Table VII.

TABLE VII: EM8 BLOCK PROPERTIES IN HydRATION PROCESS AT WATER VAPOR PRESSURE OF $47 \mathrm{KPA}, 101 \mathrm{KPA}$ AND $361 \mathrm{KPA}$ [8], [9]

\begin{tabular}{|c|c|c|c|c|}
\hline Properties & Unit & $47 \mathrm{kPa}$ & $101 \mathrm{kPa}$ & $361 \mathrm{kPa}$ \\
\hline Vapor temperature & ${ }^{0} \mathrm{C}$ & 79.69 & 100 & 139.95 \\
\hline $\begin{array}{l}\text { The temperature of } \\
\text { EM8 block }\end{array}$ & ${ }^{0} \mathrm{C}$ & $130-140$ & $150-175$ & $220-230$ \\
\hline $\begin{array}{l}\text { Volumetric gross } \\
\text { heat output after } 60 \\
\text { min }\end{array}$ & $\mathrm{MJ} / \mathrm{m}^{3}$ & 347 & 588 & 911 \\
\hline $\begin{array}{l}\text { Volumetric heat } \\
\text { output rate after } 30 \\
\text { min and } 60 \mathrm{~min}\end{array}$ & $\mathrm{~kW} / \mathrm{m}^{3}$ & $\begin{array}{l}118\left(30^{\prime}\right) \\
87\left(60^{\prime}\right)\end{array}$ & $\begin{array}{l}300(30 ’) \\
\quad-\end{array}$ & $\begin{array}{l}400\left(30^{\prime}\right) \\
253\left(60^{\prime}\right)\end{array}$ \\
\hline
\end{tabular}

As shown in Table VII, volumetric gross heat output and volumetric heat output rate directly depends on the water vapor pressure. The higher pressure leads to the higher temperature and heat output of EM8 block. Besides, with the higher temperature, the heat input (the electrical resistor power) is required higher.

For fresh air using for heating purposes in vehicles, the temperature is not required too high, so in this research, the hydration pressure is chosen is $47 \mathrm{kPa}$. With the water vapor pressure is $47 \mathrm{kPa}$, the temperature of the EM8 block within 130 to $140{ }^{\circ} \mathrm{C}$ and the temperature of the fresh air at the inlet of the reactor (the ambient temperature) is chosen from $-20^{\circ} \mathrm{C}$ to $15{ }^{\circ} \mathrm{C}$. The simulation results using ANSYS Fluent software is showed in Fig. 9.

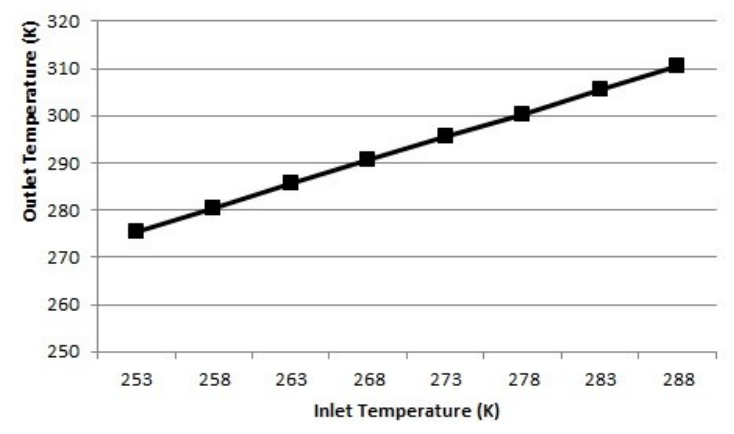

Fig. 9. The air temperature at the outlet of the reactor.

As shown in Fig. 9, when the ambient temperature is from $253 \mathrm{~K}$ (approximately $-20{ }^{\circ} \mathrm{C}$ ) to $283 \mathrm{~K}$, the air temperature at the outlet of the reactor reached from $275.5 \mathrm{~K}$ to $305.4 \mathrm{~K}$ (Fig. 10 shows the air temperature inside the reactor when the temperature at the inlet is $273 \mathrm{~K}$ or $\mathrm{O}^{\circ} \mathrm{C}$ ), fresh air at the higher temperature moves to the heating system and used for defogging or cold-start process. 


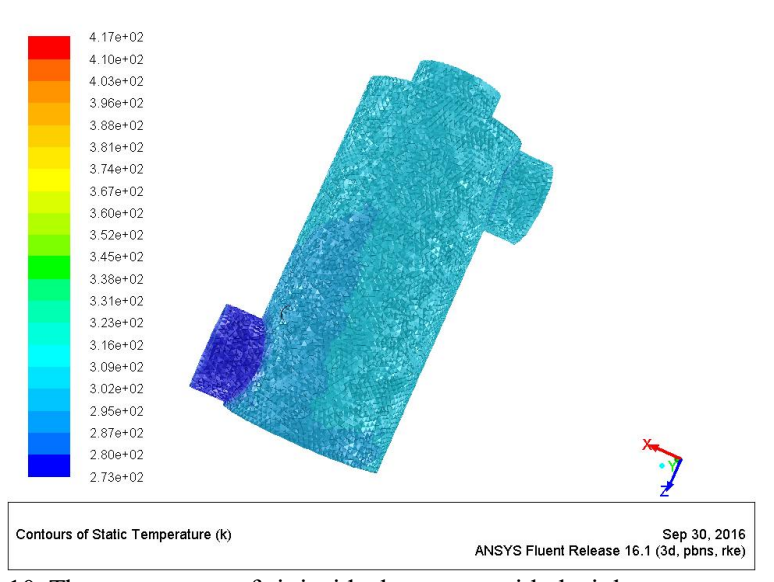

Fig. 10. The temperature of air inside the reactor with the inlet temperature is $273 \mathrm{~K}\left(0^{\circ} \mathrm{C}\right)$.

With the EM8 block mass is stored inside the reactor is $2.51 \mathrm{~kg}$ and the mass mixing ratio of $\mathrm{Mg}(\mathrm{OH})_{2}$ is $8: 9$, the mass of $\mathrm{Mg}(\mathrm{OH})_{2}$ using is $2.23 \mathrm{~kg}$. Assume that in the recharging process the performance of dehydration reaction is $100 \%$, mass of water liquid inside the evaporator in the discharging process is $0.7 \mathrm{~kg}$. At $47 \mathrm{kPa}$ and assume as, after 60 minutes, all the water liquid in the evaporator is converted to water vapor to move to the reactor chamber, the maximum heat energy requiring for the discharging process is $1850 \mathrm{~kJ}$ in 1 hour or $0.5 \mathrm{~kW}$. It can be seen that the power of resistor is small compare with energy stored in the reactor $(3.64 \mathrm{~kW})$.

\section{CONCLUSION}

The study identified the potential of chemical heat storage technology when incorporated with the engine to maximize the energy efficiency of the vehicles. The experiments were conducted to estimate the current efficiency of the engine and heat loss in the exhaust gas. The initial design was adopted to simulate the recharging and discharging process inside the reactor in one hour working time. With $0.5 \mathrm{~kW}$ resister, 3.64 $\mathrm{kW}$ of heat energy can be stored and used for heating purposed of the vehicle. It can be seen that the chemical heat storage technology is feasible, and it is expected to be applicable to a heat storage system for vehicles.

\section{REFERENCES}

[1] T. Kousksou et al., "Energy storage: applications and challenges," Solar Energy Materials and Solar Cells, vol. 120, pp. 59-80, 2014.

[2] Department of Resources, Energy and Tourism, Australian Government, "Energy efficiency opportunities. energy-mass balance: Transport," Version 1.0, 2010.

[3] K. Yukitaka, "Development of a magnesium ox ide/water chemical heat pump for efficient energy storage and utilization," in Proc. 5th Minsk International Seminar "Heat Pipes, Heat Pumps, Refrigerators", Minsk, Belarus, 2003.

[4] H. Satoshi and T. Yamasaki, "Chemical heat storage device," U.S. Patent No. 20,160,123,202, May 5, 2016.

[5] Z. Massimiliano. "A study on heat transfer-enhanced composites for a magnesium oxide/water chemical heat pump," A Study on Heat Transfer-Enhanced Composites for a Magnesium Oxide/Water Chemical Heat Pump, 2014.

[6] T. Wang et al., "Energy analysis for recoverable exhaust heat in a gasoline engine," Sustainable Thermal Energy Management in the Process Industries-Sus Tem2011, Newcastle, October, 2011.

[7] Outokumpu, "Therma 153 MA," EN 1.4818, ASTM UNS S30415, 2016.

[8] Z. Massimiliano, J. Ryu, and Y. Kato. "Composite block of magnesium hydroxide-expanded graphite for chemical heat storage and heat pump," Applied Thermal Engineering, vol. 69, no. 1-2, pp. 29-38, 2014

[9] Z. Massimiliano, J. Ryu, and Y. Kato, "Thermochemical performance of magnesium hydroxide-expanded graphite pellets for chemical heat pump," Applied Thermal Engineering, vol. 64, no. 1-2, pp. 339-347, 2014.

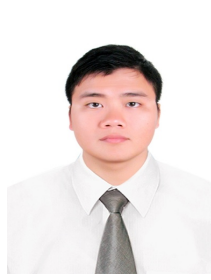

Duc Luong Cao was born in Nam Dinh, Vietnam, on November 21, 1985. He is a PhD student at University of Technology Sydney, Australia. He received his undergraduate degree in heat and refrigeration engineering field in 2008 and master's degree in energy engineering field in 2010, all at Hanoi University of Sciences and Technology, Vietnam.

$\mathrm{He}$ has been working as a lecturer at Hanoi University of Sciences and Technology since 2008 in 2 subjects: heat transfer equipment and thermal and nuclear power plant. His research is in heat transfer equipment, power plant and thermo fluids areas.

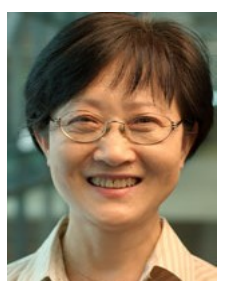

Guang Hong is an associate professor in the Mechanical \& Mechatronic Engineering Program. She received her undergraduate degree in 1976 and Master's degree in 1982 from the Huazhong University of Science \& Technology (Huazhong UST), China, and her Ph.D. in 1989 from the University of Cambridge, U.K, all in the area of internal combustion (IC) engines.

Dr. Hong has been working at UTS since 1990 Research Fellow from 1990 to 1991, and Lecturer from 1992 to 1997. She was promoted to senior lecturer in 1997 and Associate Professor in 2003. Dr. Hong's research is in the IC engines and thermofluids areas. Her research is presently focused on developing new techniques for using renewable fuels more effectively and efficiently. Dr. Hong is a core member of the Centre for Green Energy \& Vehicle Innovation (GEVI) which is one of the Research Strengths at UT

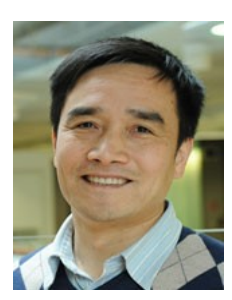

Jianguo Jack Wang was appointed as a Chancellor's Postdoctoral Research Fellow with the ARC Centre of Excellence for Autonomous Systems (CAS) in UTS early 2009. Currently he is a lecturer with the School of Civil and Environmental Engineering. He received his B.Sc. in Physics from Nanjing University, M.Sc. in Electrical and Information Engineering from The University of Sydney (USyd), and PhD in Goematics from the University of New South Wales (UNSW).

Dr. Wang was awarded China Scholarship Council research fellowship in 1997 and came to Austraia as a visiting scholar in USyd. From 1999 to 2008, he studied and worked at USyd and UNSW as a postgraduate student and research associate. He also served as a research fellow, senior engineer and project manager overseas and in Australia. With more than 20 years of broad experience in academic and industry, he is continuously developing his multi-discipline researches in sensor fusion for surveying, navigation and perception; robotics and intelligent systems; environment friendly transportation and housing; GNSS, IMU, Vision and Laser sensors modelling and data fusion etc. Dr. Wang has published over 50 refereed papers and research reports in above fields, and successfully supervised about ten $\mathrm{PhD}$ and master students. He is the peer reviewer for prestigious journals and conferences, such as IEEE Transactions on Intelligent Transportation Systems, IET Radar, Sonar \& Navigation, IEEE Robotics and Automation Magazine, Elsevier Pattern Recognition Letters, IEEE International Conference on Robotics and Automation (ICRA) and IEEE/RSJ International Conference on Intelligent Robots and Systems (IROS) etc. As a lecturer with Chancellor's Postdoctoral Research Fellow eperencee, and Core Member of Centre for Built Infrastructure Research (CBIR), Centre for Autonomous Systems (CAS) and Centre for Intelligent Mechatronic Systems (CIMS), Dr. Wang has expertise in several research areas with recognise research outcomes. His current research activities include ITS (Intelligent Transportation System), GPS, INS (Inertial Navigation Systems), sensor fusion for navigation, mapping ad perception; mining and construction automation; environment friendly transportation and housing etc. Dr. Wang has been awarded the Michael Richey Medal for the best paper of 2014 in the Journal of Navigation. 